\title{
Exploring Interactions Between NCAA Division I Athletic Directors and University Presidents: A Qualitative Study From Athletic Directors' Perspectives
}

\author{
Carrie W. LeCrom \\ Virginia Commonwealth University \\ Angela N. Pratt \\ Clemson University
}

The landscape of college athletics is rapidly changing, due to issues like conference realignment, deregulation, academic integrity, and presidential control. As member institutions work toward a shared vision and future, the role of the athletic director (AD) continues to evolve and change. Given these changes and the increase in presidential control over National Collegiate Athletic Association (NCAA) issues, this study explored relationship dynamics between ADs and presidents on university campuses from the perspectives of ADs. Research questions addressed what these interactions look like in developing a relationship between $\mathrm{AD}$ and president, how to foster positive interactions, and how to maintain them. Interviewing $12 \mathrm{ADs}$ from a variety of Division I institution types, four major themes emerged: trust and communication, alignment, respect for expertise, and formal and informal relationships. In addition, the ADs interviewed talked at length about the relationship with presidents on their own campus, as well as at the national level, where there seemed to be a lower sense of control. The authors suggest strategies for working toward these four themes as well as implications for future research in this area.

Keywords: athletic director, leadership, relationships, NCAA, college athletics

The landscape of college athletics is rapidly changing, and the future of the National Collegiate Athletic Association (NCAA), its structure, membership, and leadership is uncertain in many respects. Due to issues like conference realignment, deregulation, academic integrity, and presidential control, the NCAA's administration and membership are assessing decisions that could significantly change

LeCrom is with the Center for Sport Leadership, Virginia Commonwealth University, Richmond, Virginia. Pratt is with the Department of Communication Studies, Clemson University, Clemson, South Carolina. Address author correspondence to Carrie LeCrom at cwlecrom@vcu.edu. 
its path (NCAA, 2014). As member institutions work toward a shared vision and future, the role of the athletic director (AD) continues to evolve and change, and the need for strong leadership on the part of the athletic director is critical. However, changes within the NCAA have emphasized the role of university presidents in asserting institutional control, which refers to responsibility over "the integrity of the institution" including "compliance with NCAA rules" ("Institutional Control," n.d., para 4). Together, ADs and university presidents are deciding the future of intercollegiate athletics, on their individual campuses as well as the national stage. While there is a growing body of scholarship about the roles ADs and presidents occupy and practice separately, there is little research on how these two sets of prominent leaders interact with one another to further goals related to college sport (Branch, 1990; Duderstadt, 2000; New, 2014; Smith, 2014).

It is important to note that leadership in college athletics is not a one-on-one relationship between the president and $\mathrm{AD}$; many players impact organizational success and the structure of college athletic leadership is growing increasingly complex. However, the purpose of this study is to gain understanding of the interactions between ADs and university presidents, as leaders, and how the two groups of leaders work to build relationships. Leadership in professional settings is defined and characterized by the way colleagues interact in relationship with one another (e.g., Branch, 1990; McWorthy \& Dryden Henningsen, 2014; Skakon, Nielsen, Borg, \& Guzman, 2010). Research has shown that such relationships can be impacted by a number of factors, including members' roles within the organization, goals, perceptions, longevity and organizational challenges (e.g., Kraut, Pedigo, McKenna, \& Dunnette, 1989; McWorthy \& Dryden Henningsen, 2014; O’Neill \& Lenn, 1995; Sturgis, 2006). In addition to being impacted, the relationships fostered by leaders within their organizations can impact their members in regards to trust and communication between colleagues, organizational culture, and employee productivity (Carboni \& Ehrlich, 2013; Hsiung, 2011; Rezaei, Salehi, Shafiei, \& Sabet, 2012; Rusaw, 2000; Sturgis, 2006; Teven, McCroskey, \& Richmond, 2006). As the NCAA moves toward a more president-led form of leadership nationally, this shift could significantly impact the job of ADs, and how they interact with their presidents for the benefit of their institutions as well as college athletics nationally (Wolverton, 2014). Therefore, this study is intended to explore current interactions involved in building relationships between two sets of leaders, NCAA Division I ADs and their presidents, from the perspective of the ADs.

\section{Review of Literature}

Little has been written on the relationship between ADs and university presidents; however, much exists in regard to leadership in college athletics and other industries. Within each of these areas, subcategories exist including responsibilities of leaders, leadership theories in practice, and paths to the top. The focus of this study is on the dynamics and development of relationships between university ADs and presidents, presented solely from the perspective of the ADs. Therefore, it is appropriate to begin with some general leadership background, then hone in on the existing literature on college ADs, to better understand the context within which the realities of their experiences occur. 


\section{Leadership Studies}

Leadership and its principles remain the same across disciplines; what varies is how they are applied. From the corporate world, to the classroom setting, to college athletics, leadership remains a key concept in defining organizational success. In the corporate boardroom, CEOs have been defined as having four primary roles within their organization: vision setter, motivator, analyzer, and taskmaster (Tsui, Zhang, Wang, Xin, \& Wu, 2006). One of the most important responsibilities is to set and carry out company culture. Tsui et al. (2006) view organizational culture as both an institution and a product of institutionalization; the CEO holds a high level of control over it. CEOs are the primary sources, transmitters, and maintainers of organizational culture (Davis, 1984) and strongly impact how the company defines itself and solves problems (Schein, 1985, as cited in Tsui et al., 2006). In addition, Tsui et al. (2006) indicated that leader actions and behaviors contribute to the development of organizational culture. The results reaffirm the strong relationship that exists between a leader (CEO), culture, and overall firm performance, and could certainly be extended to an athletic department in regard to the leader (AD), culture, and overall athletic department performance.

A critical aspect of success in the corporate world relates to building effective relationships, both with employees and with the corporate board. Relationships with both of these groups have been explored within management-based literature, shedding light on their importance. In regard to relationships between organization leaders and employees, employee attitudes can be strongly influenced by the behaviors of CEOs. CEOs exhibiting relationship-focused behaviors (relating, communicating, showing benevolence, being authoritative) have employees with better attitudes, which ultimately impacts firm performance (Wang, Tsui, \& Xin, 2011). Wang et al. (2011), in the same study, found that organizations whose middle managers expressed positive attitudes toward the organization had higher levels of firm performance than others. As mentioned previously, the culture set by the CEO is critical in its trickle-down effect on middle managers and lower-level employees. In an athletic department, the Athletic Director would serve in the CEO role, with any number of Assistant and Associate Athletic Directors reflecting middle managers.

Research also indicates that building effective relationships between the CEO and the corporate board is of paramount importance. Shen (2003) performed extensive research on the life cycle of a CEO, finding that in the first two to three years of an initial appointment, the CEO is undergoing task-based learning. Because of this, it is important for corporate boards to focus on helping the CEO with leadership development during this time. After a few years on the job, as the CEO's understanding of the company and leadership capabilities have increased, the board should shift its relationship with the CEO to one that focuses on controlling managerial opportunism (Shen, 2003). The importance of this rests in the fact that the relationship between CEOs and boards must change over time to be most effective.

Within educational leadership, the issue of trust, leadership, and organizational health have all been explored in relationship to the school principal. Similar to an $\mathrm{AD}$, a school principal is responsible for setting or maintaining the culture and vision of the school, and there needs to be a healthy level of trust among the principal and teachers. Tarter and Hoy (1988) used the Organizational Health Inventory, determining that higher levels of organizational health are correlated 
with high levels of trust between teachers and principals, noting that trust is necessary in developing security in teachers. Similarly, Hoy and Miskel stated that a healthy school is "one in which technical, managerial, and institutional levels are in harmony. The organization is meeting both its instrumental and expressive needs; and is successfully coping with disruptive outside forces as it directs its energies toward its mission" (1987, p. 238). It becomes clear through business and school-related literature that the leader who builds effective relationships with key stakeholders impacts organizations significantly, and would similarly apply in the world of college athletics.

\section{Leadership in College Athletics}

While corporate and educational leaders offer insights and experiences that are clearly transferrable to college athletics, as the role of an AD in many ways mirrors that of a CEO or school principal, college athletics is unique and worth further explaining in framing this study. First, the job of an AD is demanding, not only in terms of time but responsibilities and stress as well. In a survey of NCAA Division I collegiate athletic directors, most reported working 60-69 hours per week, with $37 \%$ working more than 70 hours per week (Smith, 2014). In addition, 70\% of those surveyed attend an average of four to six events per week (Smith, 2014). The position entails a host of responsibilities, including hiring personnel, budgetary decision-making, NCAA compliance, serving as a spokesperson for the university, fundraising, management, and supporting student-athlete welfare, among others. While the focus of the AD's job in terms of priorities may be changing over time, most ADs report fundraising and budgetary issues as taking up most of their time, followed closely by issues related to coaches (Smith, 2014).

Due to the economic growth of collegiate athletics, athletic directors are now viewed more as managers than in the past (Whisenant \& Pedersen, 2004). With this shift, some schools have turned from hiring former college athletes or coaches to serve as athletic directors to targeting business executives to fill these roles (Whisenant \& Pedersen, 2004; Whisenant, Pedersen, \& Obenour, 2002). In 2014, over $80 \%$ of current Division I ADs held a master's degree, while $82 \%$ had some background in business or revenue-producing jobs (Wong, 2014). While the trend toward a business focus does not seem to be going away, some caution that experience within the university setting and college athletics specifically is still critical in new AD hires (New, 2014). Both David Brandon (Michigan) and Tim Pernetti (Rutgers) were hired into high-profile Division I AD jobs with no college athletics background, but did possess a significant amount of experience in the business sector. For a variety of reasons, neither lasted more than four years at their respective institutions, calling into question the feasibility of continuing to look for leaders from outside of college athletics to run a department (New, 2014). Considering the unique nature of sport fans (Gladden \& Funk, 2002) and the complex environment of college athletics due to factors such as managing the constantly changing NCAA and dealing with the media (Kent \& Chelladurai, 2001), those coming to an AD job with no background in the setting could be in for a challenge.

An AD is responsible for creating an environment where others can flourish, taking risks, solving problems, thinking critically, making decisions, and remaining financially savvy (Robertson, 2008). Leadership is an ever-critical piece in carrying 
out each of these duties successfully. According to Branch (1990), the ability of an $\mathrm{AD}$ to clearly delineate relationships and communication lines is a significant predictor of athletic organizational efficiency. Baghurst, Murray, Jayne, and Carter (2014) add that the ability to self-evaluate is critical to an AD's leadership potential and ability. Leadership style may also play a role in organizational success.

Theories of leadership abound, and the AD has been well analyzed in this regard, in particular transformational leadership (Baghurst et al., 2014; Burton \& Welty Peachey, 2013; 2009). Transformational leaders focus on the good of the organization over self-interests, and inspire followers to do the same (Burton \& Welty Peachey, 2009). Baghurst et al. (2014) cite transformational and situational leadership styles as those most often attributed to ADs, while Burton \& Welty-Peachey (2009) add that ADs utilizing transformational leadership generally have more satisfied followers than those using transactional leadership (Burton \& Welty Peachey, 2009).

Further iterations of this line of research note that servant leadership is the preferred leadership style above all others, claiming that transformational leadership can cause ADs to lose sight of whom they are leading, due to its focus on organizational outcomes. Servant leadership, on the other hand, focuses on the needs of the followers (i.e., how do I serve others?) and integrates an ethical component into the style (Burton \& Welty Peachey, 2013). The integration of the ethical aspect in regard to leadership is worth further exploring, as it has been shown to contribute to high performance work systems and positive organizational behaviors in other settings (Cotrufo, 2014).

Regardless of leadership style, an AD's job is constantly changing, especially given revisited topics of institutional control, an often-discussed topic among the NCAA administration and its member institutions today. Institutional control generally refers to the role university presidents play in the oversight and administration of the athletic department. According to the NCAA, the "core message" of institutional control is that "[a]ny athletics program must reflect the ideals of the institution it represents, and it is up to the athletics director to constantly inform the president...of all relevant developments within the program" ("Institutional Control," n.d. para 4). While university presidents have to set the vision and mission of the entire university, their oversight of college athletics is critical due to the amount of public interest in college athletics, and the amount of media coverage universities receive as a result. Because of the increased levels of spending by college athletics, departments are subject to high levels of scrutiny by government and other regulators, necessitating presidential attention (Bernard, 2003). As James Duderstadt, former President of the University of Michigan stated, "while it is tempting for academic administrators to regard intercollegiate athletics as merely a peripheral activity, far removed from the mainstream mission of the university, it is also clear that the unusual public visibility of big-time sports programs can place the university at considerable risk" (2000, p. viii).

This issue of institutional control was initially addressed in 1984 with the establishment of the NCAA President's Commission, the first formal involvement of presidents in the administration of college athletics (Seidler, Gerdy, \& Cardinal, 1998). Since then, presidents have exerted their influence over issues including NCAA governance and student-athlete welfare. Currently, the highest governing body in the NCAA is the NCAA Board of Governors, which is made up of presidents and chancellors ("Governance," n.d.). 
Exploring this issue in the mid-1990s, Seidler et al. (1998) surveyed ADs and presidents to gauge how they felt about their level of control over athletic departments. While most had similar feelings on levels of control at their institutions, institutional control seemed to be a topic of discrepancy. ADs perceived that they had more institutional control than the presidents felt they had granted (Seidler et al., 1998), which could lead to serious power, trust, and communication issues. More recently, due in part to scandals involving college athletic departments and coaches, issues involving institutional control are being discussed in depth once more (e.g., Ohlendorf, 2011; Patterson, 2015; Powers, 2013).

As demonstrated above, a host of researchers have published work on leadership and college athletic administration. However, Seidler and colleagues (1998) are one of the few to have looked explicitly at the relationship between college ADs and their presidents. Due to the changing outlook of presidential control with regard to the NCAA, it is an appropriate time to revisit this topic by exploring the dynamics of the relationship between these two university leaders. Therefore, the current study took on an exploratory approach to investigating the dynamic between ADs and presidents. While many approaches could have been enlisted, based upon the findings of the literature discussed above, the authors left the methodology open for exploration and interpretation.

\section{Theoretical Framework}

Thorough a meta-analysis spanning four decades, Dirks and Ferrin (2002) compiled hundreds of data from trust-in-leadership studies. The authors concluded that, theoretically, these studies are either based on the leader-follower relationship, or on the leader's character and how it influences relationships. However, Dirks and Ferrin (2002) posit that trust in leadership is a social exchange process, and that these two theoretical bases are not mutually exclusive. Because the authors were exploring relationship dynamics (social exchange processes) between ADs and presidents, Dirks and Ferrin's 2002 study was a fitting theoretical basis. The authors noted that high-quality relationships, care, and concern are all about relational issues, and both the leader's character and the leader-follower relationship should be taken into consideration when studying trust in leadership. This idea framed the questions that were developed for the interviews, and is what guided the research.

\section{Research Design and Analysis}

The research questions for the current study focused on how ADs characterize the relationship dynamics between themselves and their presidents, and how they actively facilitate interactions in an effort to build relationships. In looking for ADs' shared understandings of the relationship dynamics with their university presidents, a qualitative, phenomenological approach was taken, in which the researchers collected and analyzed the lived experiences of ADs, expressed through their own words. Specific research questions were as follows:

1. How do ADs characterize the relationship dynamics between themselves and their presidents? 
2. How do ADs actively work toward interacting with presidents in an effort to build relationships?

3. How do ADs and presidents maintain positive relationship dynamics?

\section{Participants}

This study has been conducted in a manner consistent with constructivism, a philosophy of inquiry that affirms realities as multiple and socially constructed, as well as context dependent (Guba, 1990). Being an AD for a NCAA Division I intercollegiate athletics department is the social construct that creates the cultural context within which the concepts of leadership and relationship dynamics between ADs and presidents were explored. The researchers chose this construct because ADs of Division I institutions generally garner an intense and visible degree of scrutiny by media and other stakeholders, as do their university presidents (Hardin, Cooper, \& Huffman, 2013; Legon, Lombardi, \& Rhoades, 2013).

Twelve ADs from a variety of NCAA Division I institutions were interviewed for this study. Initially, convenience sampling was used to identify a few ADs who had already established trusting relationships with the researchers. In this initial set of interviews (approximately eight), the researchers considered diversity in who was interviewed, including gender, geographic location, type of school, and experience. After these initial interviews, other participants were recruited using a snowball technique, whereby the researchers asked previously interviewed ADs for references of others who might consider participation in the study, and who might provide rich, descriptive opinions on the topic (Krauchek \& Ranson, 1999). Pseudonyms have been used to protect participant anonymity. Demographic information to demonstrate the diversity of subjects is included in Table 1.

\section{Data Collection and Analysis}

After receiving Institutional Review Board approval, interviews were conducted over the telephone, lasted approximately one-hour each, and were recorded. One researcher conducted each interview, using a discussion guide to conduct the interviews, which provided a loose and flexible framework to help build trust and rapport with participants, and encourage them to talk about their experiences. The discussion guide was piloted with two ADs at the schools where the researchers reside, and was additionally vetted through two retired ADs. It began with general questions asking about the participants' roles as ADs, then transitioned into questions about how participants understand leadership (in the context of being ADs). It continued by asking how ADs characterize the interactions and relationship dynamics between themselves and their presidents, as well as how ADs go about implementing and maintaining such interactions. As the interviews proceeded, new prompts were added as participants introduced their own issues and concepts. In some cases, prompts were changed to correspond with categories suggested by previous participants (e.g., "Some participants have commented about ' $\mathrm{x}$ '. Has that been a part of your experience?").

The lived realities and experiences expressed by the participants in their own words are the data used for "grounding" the theory for this research (Glaser \& Strauss, 1967). The semistructured interview recordings were first transcribed 


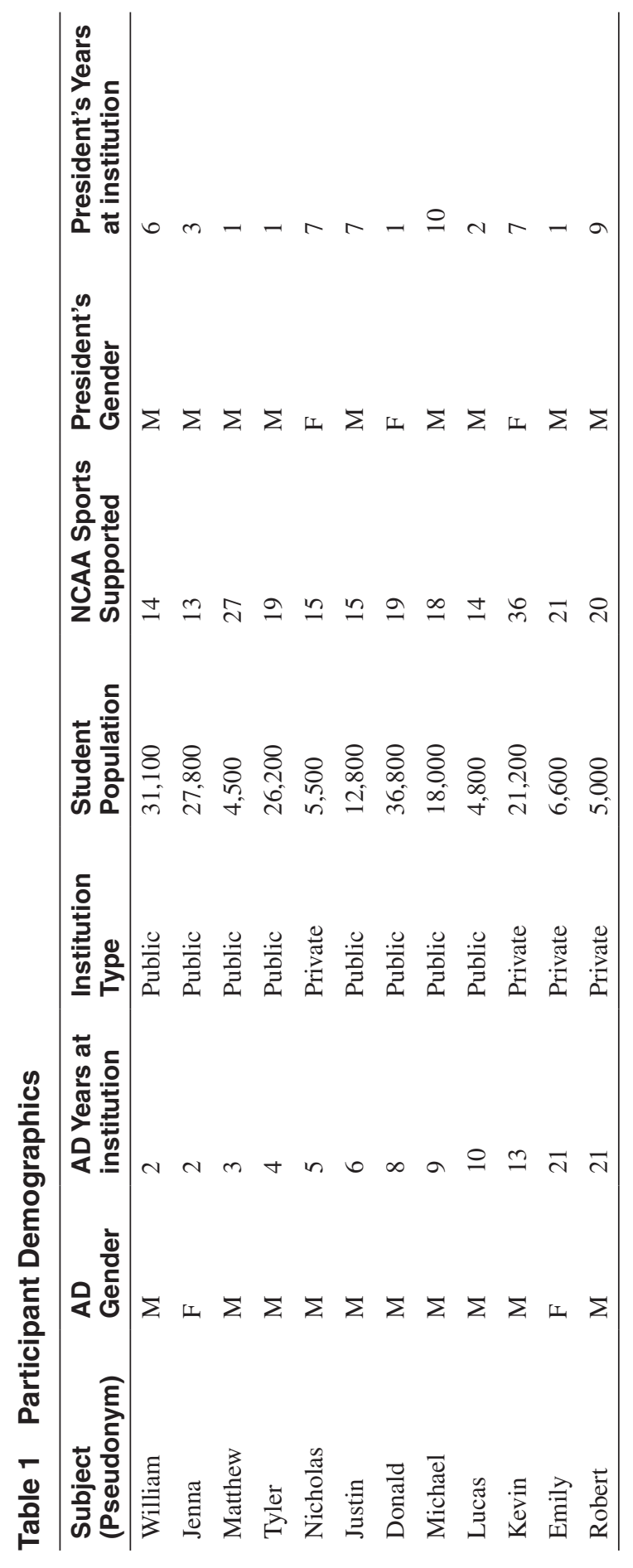


verbatim. Two independent researchers coded and analyzed the transcripts individually. The data coding procedure used analytic codes, categorization, and themesearching (Glesne, 1998). The researchers-individually first, then in discussions together-analyzed and coded the interviews for emergent themes and shared understandings, using comparative analysis procedures to further the discovery of grounded theory (Glaser \& Strauss, 1967). Utilizing analytic induction, the researchers looked for conceptual categories within the text of each interview transcript, and then for shared understandings (confirmation of the conceptual categories) between the texts of all interviews. The researchers then illustrated each conceptual category with evidence in the form of quotes from participant interviews. The goal with these reference points is not to "provide a perfect description of an area, but to develop a theory that accounts for much of the relevant behavior" (Glaser \& Strauss, 1967, p. 30).

For organizational purposes, hand-written and computer-assisted methods (Microsoft Word) were employed during coding. Lastly, themes were constructed from the relationships among codes that were analyzed. The researchers used researcher triangulation by enlisting a multimember research team in the process (Blaikie, 1991; Fossey, Harvey, McDermott, \& Davidson, 2002). Credibility and dependability were addressed through member checking and audio-recording the interviews (Lincoln \& Guba, 1985). In addition, extensive notes were kept describing the data collection process, categorization, and how decisions were made.

The goal of the researchers was to attain redundancy, or "mutual consistency" and "saturation" of data, as described by McCracken (1988, p. 50) and Jensen (2002, p. 247). At the point of mutual consistency, no new categories of data emerged from participants. The researchers found mutual consistency of the data by the time they reached 12 interviews. The themes that emerged from these interviews provide a clearer picture of how NCAA Division I ADs characterize the relationship dynamics between themselves and their presidents, as well as how interactions are implemented and maintained.

\section{Results}

The purpose of this study was to explore the relationship dynamics between university athletic directors (ADs) and presidents, from the perspective of ADs. While responses were varied, four main themes emerged in a consistent manner. Those themes included: trust and communication, alignment, respect for expertise, and formal and informal relationships. Each of the themes, discussed in detail below, was suggested by participant ADs over the course of their interviews, and included discussion about the dynamics of their relationship with their AD's and how interactions are implemented and maintained. Evidence for each theme is illustrated in the form of quotes from participants.

\section{Trust and Communication}

When ADs were asked to describe what interactions are involved in building relationships between ADs and their presidents, most of their first-offered responses centered on "trust" and "communication." Comments such as this one from Kevin exemplifies the top-of-mind nature of these concepts: "It would be one where 
there is trust and one where there are open lines of communication." Consistent with this quote, trust and communication were most often discussed together in an interwoven manner that implies the close connection participants saw between these concepts. The participants spoke about trust in light of the conversations with and messages conveyed between themselves and their presidents. Likewise, they discussed communication in conjunction with the trust that must be inherent in that process. For these reasons, the authors have grouped "trust" and "communication" together, as opposed to parsing them into separate themes.

Regarding trust, ADs described how it is the bedrock of their credibility when it comes to communicating with their presidents. According to Donald, "It's all about the trust thing. If [your president doesn't] trust you, then I think that's when that relationship gets really difficult because they just don't necessarily believe in exactly what you're saying. They trust somebody else who's telling them something different." Participants also spoke about how they went about building trust with their presidents, such as Lucas: "Now I know of course trust has to be earned...it's built up through small, hopefully at first, small moments of adversity, less adversity but big decision-making and then allowing the other to do their job." Walter compared the development of trust between ADs and their presidents to "the way it evolves between coaches and kids," where an authentic relationship is built, not a one-way "dictatorship" full of "mandates" from the president.

Trust may also be shown by presidents allowing ADs to make major decisions that may involve a degree of risk, as well as ADs accepting their presidents' responses to new proposals. Justin outlined this idea in his description of trusting interactions between an $\mathrm{AD}$ and a president:

...willingness for your boss to let you take risks that are calculated and not negligent...you have to have trust in the person that you're working with that when they tell you for whatever reason no, that they are making the best decision for the university.

Regarding communication, ADs stated the importance of making sure the president knows what is going on with athletics, is well informed, and is never caught off guard. Three participants explained their views this way: "I've got to make him or her look good. I don't want my president to get into any decisions that are going to tarnish his or her image in any way...We're all here working for the president, so let's figure out the best way to work for him or her, let's figure out the best way to make him or her look good. If we do that, we stay out of trouble," and "I work in part to make him or her look good, in whatever circumstance it is. First, find out what the president's expectation is, talk about trust, and communicate well" (Lucas).

Some ADs also described a "no-surprise rule" that they believe should characterize ADs' dialogue with their presidents. The term "no surprises" came up in the majority of interviews, with ADs noting that one of the easiest ways to tarnish the relationship with their president was for him or her to feel uninformed or caught off guard. The president is expected to have a good grasp on everything that goes on at the university, so ADs need to communicate things that are critical, or that might need to be brought to the attention of the president, without overwhelming him or her with unimportant details. William described it as "mak[ing] sure the president has all the answers before he takes the test, and to keep the president briefed on things that are critically important." Tyler concurred: 
Probably one of my biggest tasks is making sure the president's not surprised with anything...I've got to make sure that if we have run into a problem, when I found out about it, he does too, so that that level of confidence is not damaged.

Some ADs emphasized honesty and authenticity in conjunction with the idea of the "no-surprise" rule. For example, Jenna said, "My approach, my personality is being really authentic and you know, trying to share information, you know, stuff that [the president is] interested in and never let them be surprised, if I can help it. Such things go a long way." Justin echoed those sentiments:

I just try to be myself and that is treat others the way I want to be treated and to try to keep in good communication within reason. I don't think it applies to just athletics, but any good hierarchy, the no surprise rule. I don't need to know everything that's going on with people that directly report to me, but I need to know the big stuff.

In addition to building trust with presidents by being honest, authentic and forthcoming in their communication, ADs said that they also needed to be careful about burdening their presidents with too much communication. Tying back into the theme of trust, ADs discussed the importance of recognizing that their presidents expect them to be able to handle some matters on their own.

I think what you do not want to do is throw a question [the president's] way and say, "Hey, what do you think I should do?" That's what athletic directors are getting paid to do. What I would do is if it involved, let's say an arrest, once I found out about it, I would immediately alert the president so that if it appears in the paper, which it always does here, that he or she knows about it in advance (Tyler).

In regards to communication with ADs from their presidents, participants had the same expectations as they had for themselves, in principle.

As long as there's an ongoing conversation about whatever the situation is, I think that'd be fine and especially at the level where some things have the potential to be very, very serious...that is absolutely the situation where you want president and $\mathrm{AD}$ on the same page. Talking about where you're going. Talking about what you're doing and talking about how you're going to address it with an eye towards the institution's reputation, with an eye towards the student athlete's experience (Nicholas).

However, some pointed out that, because the scope of presidents' jobs are so much wider, ADs do not necessarily need to be pulled in on presidents' major decisions as much as the other way around. The exceptions would be to know about any decisions that would directly affect athletics.

There are not a lot of things in the big picture that would affect us... Not too many times where I'll be leaning on the president to get back with me on something because they just don't delay, really. I really don't have any examples where I've ever said, "God, I wish you had told me that" (Tyler). 
Even so, participants indicated that they did not want to hear indirectly that their presidents have issues with athletics.

I don't mind a president that calls up and talks to me and says, "I think we have an issue and I want to talk to you about it." That is perfectly fine. What is annoying to most athletic directors is when they see a roundabout from other people that, "Did you know the president is upset with X?" I usually say, "The president is upset with X, and if he or she's that upset about it, I hope that the president will tell me what they're upset about so that I can basically respond" (Kevin).

\section{Alignment}

The term "alignment" comes from the participants' description of the way in which ADs and presidents must be in sync when it comes to major topics and issues (mission, core values, priorities). For example, Nicholas outlined the areas where and why he saw alignment as important: "Are you aligned with values? Are you aligned with resources? Are you aligned with direction? Are you aligned with goals? You can go a lot of good places if you're on the same page."

Several participants in this study began their interviews by discussing the importance of the ADs and presidents being aligned in their vision, mission, and core values. One said, "My mission has to be in alignment with his [the president's]. I cannot be divergent from what he's doing" (Matthew). ADs similarly thought that one of the primary aspects of their job was to carry out the mission of the university through the athletic department. Kevin described this concept as being part of "something bigger:"

It's not just pushing the athletic department forward without the context of what the president is trying to do and what the institution is trying to do... we're part of something bigger. I think the best athletic directors understand that, and they fit. Their goals, their objectives, their missions, fit with the overall mission of the institution.

Jenna concurred with this view, and discussed the importance of actions in terms of demonstrating athletics' alignment with the institution. "It's important that we're part of an educational institution to me, and that we [in athletics] demonstrate that in the things we do. If I can message like that and make sure that [the president] also see[s] me operating in that way, that takes time."

Both of these ideas relate back to the importance of being on the same page or in sync with one another when it comes to major university issues. That is difficult to do if the AD is unclear about university priorities. Tyler indicated the importance of clarifying those priorities with the president, specifically in regards to what the president expects: "I would also ask the president what's the most important thing in his or her eyes because you always want to please the boss. Sometimes you may not know what the boss wants unless you ask."

Along with this is the idea that ADs also need to understand their presidents' vision for university athletics. Nicholas said that ADs and their presidents must be "in alignment about the direction of the [athletic] program...If you have a president who values athletics, wants your athletic program to be successful, you're not 
going to have too much difficulty trying to advance your program. If you're in a situation where your athletic program is tolerated, it's going to be difficult to move much forward." Statements such as these show that participants view alignment as a necessity within the relationship dynamics with their presidents, as well as for their individual success.

Along with this is the idea that ADs should demonstrate alignment by avoiding public disagreement with their presidents. According to Justin, "there's going to be times when we disagree, and I got to make sure that I'm a team player whether it's in my staff, my student athletes, the media, to donors, don't give off a different vibe so that they think that there's not harmony within the ranks." Ultimately, being in and demonstrating alignment is very important to both presidents and ADs in regard to accomplishing goals and maintaining a positive reputation.

\section{Respect for Expertise}

Participants were unified in their belief that positive relationship dynamics between ADs and presidents are incumbent upon presidents respecting their ADs' expertise. Lucas described that he expects the same respect for his expertise in athletics that he gives to his president regarding academics: "I am the athletics person, and I don't try to step outside of that and tell [presidents] what they need to be doing when it comes to educational policy, and in the same sense, I don't expect my presidents to be telling me how to react to an athletic issue that they don't know as much about." Similarly, Matthew used the term "stay in my lane" to discuss mutual respect for expertise between him and his academic counterparts:

I'm not an expert in being a president. I'm not an expert in academics. I think I know more about college athletics than anyone else here and by extension of that I stay in the college athletics lane...I am not going to pass judgment on what the dean does, or what the vice president of student affairs does. That's not my lane.

Nicholas also used this terminology to warn against the propensity for some to overreach into athletics: "Stay in your lane. Don't start deviating into stuff that's not in your area of competence...[T] his is probably one of the most interesting things related to athletics that you don't find in any other places. This isn't just a presidential piece, but everybody thinks they know what they're doing as it relates to athletics."

According to participants, this respect can be demonstrated in a variety of ways, such as giving ADs the freedom to make important decisions, referring athletics questions from outside parties to ADs, and consulting ADs before making decisions that would impact athletics. Walter contrasted the respect for expertise that he receives from his president from his experiences while interviewing for AD positions at other institutions: "I go to a lot of campuses that I have no interest in being a part of. I don't really understand why my presence is needed, maybe so everyone else gets noticed."

In addition, "micromanaging" was a term offered by several participants to describe what presidents should avoid doing to show their ADs that they respect their expertise in athletics matters. For example, William said that, "The president has to have a trust, a shared trust there, so when the president knows the AD is 
doing all the things the AD is supposed to be doing and not getting involved in micromanaging."

Most ADs discussed the issue of respect for their expertise from a collective perspective: how groups of presidents at a conference, regional, or national level are responding to or involving their ADs in major athletics issues. For example, Justin expressed concern about groups of presidents whose level of expertise regarding intercollegiate athletics does not match the level of athletics-related decisions they are making without consulting ADs.

That's important to me that from the president collectively they let ADs be in a position where we can make daily decisions. That's what I think we felt as ADs has been going on quite a bit. They are micromanaging in ways that they are not only not trusting us, they are not the experts in a lot of these things they are micromanaging. Then we have to fix them or deal with them.

Kevin also discussed negative outcomes resulting from policy groups of university presidents who do not consult ADs about athletics decisions:

Whenever you have policy groups made up of people because of their position rather than their full expertise, the policy group could make misguided judgments. If you have a council of presidents who make decisions on athletic matters without real input and without real dialogue with athletic directors, there's a potential to have many unintended consequences through your actions.

Some participants blamed the NCAA for giving presidential groups too much power, and encouraging them to rely on the guidance of the NCAA leadership instead of ADs. According to Jenna, "I certainly think that the decisions were made without real understanding of impact and applications, by a group of chancellors and presidents [who] had some knowledge, but were certainly influenced by national office staff and others. Without a whole lot of interaction and communication with people who are every day at work within college athletics."

However, some ADs acknowledged that individual presidents' interest in athletics issues on their own campuses makes sense because of the tremendous attention that sports bring to their campuses, as well as the potential impact on presidents' careers. Tyler reflected on both of these considerations:

(S)o many times, athletics is...it can be the undoing of a president's ability to lead an institution. The president has to treat athletics a bit more hands-on than he or she would, say, the journalism school or the college of engineering, things along those lines. It's different because it gives more publicity than any other department. There's no ESPN for academics right now.

None of the ADs in this study expressed frustration with their own current presidents in terms of respect for the ADs' expertise about athletics. It was clear that, collectively, their greatest concern was regarding groups of presidents who have power over athletics policy, especially at the national level.

\section{Formal and Informal Relationships}

The final theme that emerged through participant interviews was the importance of having not only a formal, but also an informal relationship with your president. 
While not all ADs in the study felt that they had both a formal and informal relationship with their current president, most indicated that the balance between the two was ideal. "I think the biggest thing is that you have to develop a working relationship and a personal relationship with the president," said Robert.

Participants characterized a "formal" relationship as one in which there are regular meetings between ADs and presidents, where the conversation is focused on specific topics. Justin described his formal meetings with his president that take place "roughly weekly. We go over things that he's got on his list or I have on mine, and what I try to do is bring things that are either finishing up a topic he's asked me to check on or that I want to finish up."

Kevin advised new ADs to "go and actually get an appointment to see the president, even go and have lunch with the president. I would say that what you want to do is set up a regular...once or twice a year you've got a little audience with the president." But he also discussed the impact of presidents reaching out to make time for their ADs: "That does so much, because it values [athletic director's] opinion, their perspective. It creates a bond. It's good. It recognizes the athletic director as one of the key people managing and leading a very significant part of the organization."

On the other hand, activities such as playing basketball together, meeting for lunch outside of a "formal" meeting schedule, or texting back and forth were examples of ways that ADs and presidents build the more social and/or informal relationships. Robert put it this way:

I think one part of it is that it's not just on what I would call the official relationship. I think developing a rapport with the individual, so that they know who you are, and you have an understanding of who they are...If they just see you as a subordinate, you can't quite be as open as you'd like to be with what you say, and vice versa.

Emily described how developing a positive informal relationship with her president can benefit her as an AD: "I want [the president] to like me as a person because I think when it comes time to making touch decisions whether they go my way or not, it's just an easier thing to do." William pointed out that the way informal relationships play out between ADs and presidents depends on individuals' interests and circumstances:

I've worked for a president before that he and I had soup every two weeks on a Wednesday and just talked about different things that were going on because that helped us build the relationship. Now, I work for president that we text back and forth because he's got so many other things going on he can read it as it goes.

One of the things that appeared to be a key issue was access, and those ADs who had both formal and informal relationships with their presidents seemed to indicate feeling a more secure level of access to the president. Donald stated, "That's the most key thing... having access," while Emily said, "For me, you need to have access on a pretty regular basis." Those with strong formal and informal relationships felt that they did not have to wait until their formally scheduled meetings to reach out to the president if there were issues to be discussed. There was a mutual respect on numerous levels, which allowed for greater levels of access and mutual respect. 
Interestingly, it seemed that most participants craved the informal relationship. For those who had previously served under a president with whom they felt they had a strong relationship, they were pining after the informal aspects of that in their current setting. They were, however, quick to point out that some of that comes down to personalities meshing well together, which is not always the case. Walter summarized it well saying, "There's got to be a personal relationship or a friendship, and I think it's got to be a two-way street."

\section{Discussion}

This study offered a look at a subject that is underexplored in the sport-based literature: relationships between university presidents and directors of athletics. While few would deny that these two parties must work in tandem on any university campus, little has been published to date that identifies how the two interact on a regular basis, on campus or outside campus. The current study, in exploring this topic, found four major themes that were identified by participants as essential to relationship dynamics: trust and communication, alignment, respect for expertise, and formal and informal relationships. Each of these is discussed below and framed in the context of the power dynamics at work between athletics and university administration, the changing landscape of college athletic administration, as well as the current body of literature regarding leadership and workplace relationships.

\section{Trust and Communication: "No Surprises". . An Implausible Ideal?}

An essential part of the relationship between ADs and presidents, according to participants, is following the "no surprises" rule. ADs, to a person, took very seriously their role in making sure their presidents were well-informed about anything related to athletics that might show up in the media. This was especially the case for anything negative that might put the institution in a bad light. However, the immediacy of the current media environment is likely making "no surprises" more essential and challenging. As publications and TV news have moved online, in addition to the 24-hr cable news timeline, media are in constant competition to be first with the latest story. Reporters might not wait for any confirmation or interviews before running a story, which often results in inaccuracies. However negligent those inaccuracies might be, presidents and ADs alike will still find themselves in the position of correcting misinformation and clarifying their positions.

Social media adds to this challenge by the speed in which nonmedia publics can also participate in the reporting and spreading of information, as well as stirring a groundswell of public pressure on ADs and presidents to act. Even the most proactive ADs cannot stay ahead of every social media story involving their departments, and must also be selective about what they choose to investigate further, much less report to their presidents. This presents a challenge to ADs who want to follow the "no surprises" rule with their presidents, yet not overwhelm them with information. As news becomes less scheduled and more immediate, ADs and presidents will have to come to new understandings about what constitutes a story worthy of response (i.e., trending, content, source), and how best to compose and deliver that response. 
With such a wide scope of constituencies to oversee, it seems that presidents might benefit from having ADs who are proactive about giving them a "heads up" about any issues headed their way. However, to what extent must presidents be informed? And what happens after the informing takes place? The answer to these questions may indicate more about the power dynamics between ADs and presidents than anything else, while also reaffirming Dirks and Ferrin's (2002) assertion that trust in leadership is a social exchange process.

Regarding the former question, the ADs in this study indicated that they usually informed the presidents on major developments, so as not to overwhelm them with too many details. However, it is not always clear what differentiates a major development from a minor one. For example, it is not uncommon for athletic directors to receive complaints from student-athletes about coaches; participants such as Nicholas discussed this in their interviews for the current study. But in some cases, such as at the University of Illinois, a few complaints may lead to a lawsuit, which may lead to more student-athletes coming forward with lawsuits, and finally a full-blown athletics crisis with public pressure and national media attention (Ganim, 2015). At what point in such a scenario does the "no surprises rule" kick in? When and what carries enough gravitas to have a conversation with one's president is far from clear, which indicates that the "no surprises" rule might be more difficult to follow than its simple name and concept implies.

This leads to the latter question of action and responsibility. If ADs inform their presidents about major developments, does that necessitate presidential responses, or simply approval of ADs' responses? In the men's basketball coaching abuse scandal at Rutgers University, new president Robert Barchi approved AD Tim Pernetti's suspension of head coach Mike Rice for allegations of player mistreatment (Star-Ledger staff, 2013). However, once video was released to the media of practices showing Rice shoving and shouting gay slurs at players, Barchi was criticized for not insisting that Rice be fired months earlier, when evidence of the abuse first came to light (Zernike, 2013). Rutgers ended up firing Rice, and Pernetti resigned under pressure (Associated Press, 2013). However, Barchi did not step down himself, which led to a new round of criticism that the AD was used as a scapegoat for poor decisions that the president approved (O'Keeffe, Red, Armstrong \& Vinton, 2013). The law firm conducting the post mortem investigation indicated that Barchi did not view the incriminating video evidence until after it had been released to the media, and therefore had not been sufficiently informed in the first place (Heyboer \& Sherman, 2013). In this type of "damned if you do, damned if you don't" scenario, the only thing that is clear is that simply keeping presidents informed will not be enough to protect ADs in situations involving a high degree of public pressure and media attention, especially if the initial information is later deemed to have been insufficient.

\section{Alignment: Situational vs. Core-Level}

Alignment was defined through this study as the ability to be in sync in regard to major university issues. Hoy and Miskel (1987) discussed the importance of a school where "technical, managerial, and institutional levels are in harmony" (p. 238). Not only does this alignment help the AD and president set priorities that are in line with the direction of the university, but it also trickles down to areas such 
as media and fundraising. The media and fundraising roles that each play at their institutions are critical, and alignment and good communication are paramount in their effectiveness. Recent studies indicate that fundraising is becoming a large share of how ADs and presidents spend their time (Smith, 2014; Sturgis, 2006). Within the university, presidents and their vice-presidents for institutional advancement work as a team to successfully accomplish fundraising goals (Sturgis, 2006). However, ADs and their athletic foundations are solely focused on athletics related fundraising goals, and are often removed from the normal reporting and accountability environments of others at the institution; athletics typically operates separately from, but simultaneously with, general institutional advancement (Duderstadt, 2000). Some of the publics that ADs and presidents reach out to for development funds are the same corporations, families or individuals. These publics may have an affiliation with academics and/or athletics because they are community employers, local leaders or prominent alumni. Coordinating various "asks" to such businesses and persons is necessary to present a united front, as well as to avoid burdening people or groups with too many requests.

This coordination, or alignment, presents an opportunity for ADs and presidents to work together to develop strategic plans that allow both parties to accomplish goals. If trust and open communication have been established, as indicated by the ADs in this study, it would seem that the negotiation over shared fundraising sources would proceed in a positive and professional manner. However, this can only happen if $\mathrm{ADs}$ and presidents are also in alignment regarding their relative positions of power. If an $\mathrm{AD}$ and president see each other as sharing power in a system of mutually agreed-upon goals and priorities, then strategic planning and negotiation over donor and partner relationships should proceed smoothly and productively. In such an ideal situation, the focus of both would be the greater good, in addition to the mutual success of both parties. In a less-than-ideal relationships between ADs and presidents, this negotiation might be derailed by conflicts related to power and ego, competing priorities, and/or a lack of respect for the other's position.

Therefore, it seems that surface-level alignment is not indicative of anything more than situational expediency, and the true ideal to strive for is core-level alignment that addresses power and priorities. In today's higher education and collegiate athletics environments, this ideal may be difficult to reach, as turnover rates for both positions are climbing (Kiley, 2012b; Smith, 2015). Such turnovers-experienced by many of this study's participants, either because of their own moves or those of their presidents-mean that ADs and presidents not only have less time together to develop the type of relationships that facilitate core-level alignment, but the nature of their progress toward upward mobility in their professions may lessen the impetus of one or both parties to do so. Future research should explore the depth of AD-president alignment and its impact on institutional priorities and decision-making.

\section{Respect for Expertise: Micromanagers Need Not Apply}

Respect is an often-reported characteristic of leaders, and it was clear that the need to be respected for their expertise in terms of college athletics was an important factor in this study. The manner in which the ADs discussed this facet of professional respect may be indicative of complex power dynamics at work in today's 
higher education environment, especially at institutions with high-profile athletic programs. The ADs in this study often described their interactions with their presidents in deferential terms; for example, seeking an audience with the president on limited occasions (e.g., Kevin), seeking to please "the boss" (e.g., Tyler), taking care of the president's informational needs (e.g., Jenna), not expecting equal levels of information from the president in return for what the AD offers (e.g., Tyler). This deference suggests that ADs see ultimate institutional power in the hands of their presidents.

However, ADs in this study also made it clear that they expected to be consulted on all athletics related issues, and trusted to carry out decisions on behalf of the athletic department without interference from the president. The ADs in this study felt very competent and well trained in the business of college athletics, and viewed their hiring as a unilateral vote of confidence in their ability to make the final call in all athletics-related decisions. The fact that many institutions are more often hiring ADs with business backgrounds and higher levels of education seems to lend support to this perspective (Whisenant \& Pedersen, 2004; Whisenant, Pedersen, \& Obenour, 2002; Wong, 2014). Such clear-cut delegation suggests that ADs see ultimate athletics power in their own hands.

Where these power dynamics of deference and delegation come into conflict is when a situation arises in athletics that affects the image and viability of the entire university. For example, a number of high-profile scandals in recent years have caused members of the media, government, and the general public to question who is ultimately responsible for athletics-related crises. It is rare that only the AD is involved in decisions leading to or addressing a crisis, and therefore it is also rare that only the AD is held responsible. Some university presidents have resigned or been fired outright in the wake of scandals related to athletics, such as those at the University of North Carolina (resigned) (Kiley, 2012a), Pennsylvania State University (fired) (ESPN News Services, 2011), and the University of Missouri (resigned) (Eligon \& Pérez-Peña, 2015). This reality calls into question the notion of presidents truly delegating full and complete responsibility of athletics to ADs. Even if that is their intention, public pressure and scrutiny surrounding athletics may prohibit this ideal from being fully realized.

In addition, the power dynamics tied to the idea of respect for expertise extended beyond the individual relationships our participants had with their own presidents, into conversations about leadership at the national level. Participants in this study characterized on-campus respect for expertise very differently than national-level relationships between ADs and presidents as groups. When discussing relationships with past or current presidents on their campuses, ADs expressed respect for expertise in terms of self-efficacy, a concept defined by Bandura (1986) as a belief in one's capability to act in a given situation. ADs demonstrated self-efficacy in that they saw themselves as capable of and having an active role in developing positive relationships with their presidents, as well as working with their presidents toward achieving goals. These responses suggest a sense of power among ADs: as individuals and as shared with their presidents.

But when the conversation turned to national-level relationships, ADs' expressions of self-efficacy diminished considerably, not only for themselves, but for ADs as a group. Many participants said they had little to no influence as individuals regarding national-level policy discussions; and several went further to say that 
they had no interest in getting involved, either. Probed further as to why this is the case, ADs consistently pointed to the various NCAA committees of presidents' lack of respect for the expertise of ADs. Therefore, many of the ADs interviewed had little hope of impacting national-level decisions, even as a group. These responses suggest that the sense of power ADs feel on campus dissipates in the face of the politics of national athletics governance.

This discrepancy in perceptions of on-campus versus off-campus power is clearly an obstacle for ADs who want to influence national policy. What is troubling in the ADs' responses from this study is the sense of hopelessness they expressed regarding the national stage. Many said that they focused on their own campuses and conferences, as anything beyond that would be an exercise in futility. Because they believe they have the most respect for their expertise in these realms, they also believe they have the most power to effect change there. However, if the feelings of the ADs in this study are shared by many of their colleagues, it is also plausible that there is a silent majority who could be working together to accomplish nationallevel agendas. If this is the case, perhaps it is not respect for expertise from their presidents, rather communication of respect for expertise among and between their counterparts at other institutions that will give ADs confidence to challenge the national athletics governance status quo. Considering the magnitude of the current national-level discussions and lawsuits regarding issues such as student-athlete compensation (Tracy \& Strauss, 2015), sexual assault (Fagan, 2014), graduation rates of minority student-athletes (New, 2016), and concussion policies (Solomon, 2015), it seems that this theme of respect for expertise related to power relationships between ADs and presidents (and perhaps ADs and other ADs) is worthy of future exploration.

\section{Formal and Informal Relationships: The Importance of Intentional Effort}

Ultimately, it was clear through this research that building relationships with their presidents is the key to a sense of self-efficacy and influence for ADs, especially on campus. As previously mentioned, the formality described by several ADs in their relationships with their presidents (e.g., setting up formal meetings), suggests a degree of deference toward their presidents. However, the informal relationship strategies touted by many ADs suggests that forming friendships beyond the traditional workplace context helps ADs raise their esteem by creating situations where the $\mathrm{AD}$ and president interact as peers. For example, playing or watching sports together, and going out for casual meals are things social friends do. While there may be power dynamics even between friends, they are less pronounced than a superior-subordinate work relationship. In this informal context, both the AD and the president may be exhibiting a form of soft power, where developing mutual likeability aids in their mutual understanding of one another.

As authors Wang et al. (2011) and Tarter and Hoy (1988) stated, employees can be strongly influenced by their leaders, and this was clearly seen in how ADs defined relationships with presidents. Those who considered themselves to interact formally and informally with their presidents, and who felt healthy levels of trust and communication, were very comfortable with their on-campus leadership balance. What remains to be learned is whether university presidents also intentionally 
develop this formal-informal relationship with their ADs. If the ADs are doing all the work, and presidents are merely responding, then there is still a deferential power dynamic between the two, even if it feels like a social friendship. For ADs, this might mean having less influence and security than they might consider ideal. Future studies from presidents' point of view might aid in understanding how formal and informal relationships with ADs impact power dynamics, priorities, and decisions.

\section{Limitations and Future Research}

This study, like others, was not without limitations. First, this study examined the relationship dynamics between ADs and their university presidents from the perspective of ADs alone. While the ADs' perspectives are limited to their realities as they have experienced them, the themes from this study provide data that will be useful as sensitizing concepts for future interviews with university presidents. In the meantime, focusing on ADs allowed the researchers to better understand their social worlds without conflating their thoughts with that of university presidents.

Second, the number of participants in this study was small, at 12 , but was diverse, representing different types and levels of Division I institutions, a range of years of experience as an $\mathrm{AD}$, as well as both male and female participants. In addition, the researchers were looking for points of saturation and repetition in the interviews with regard to content gathered, and had reached that by the 12 th interview. This study offered an initial look at an important topic from a phenomenological perspective, so it was focused on gathering rich, in-depth information from a smaller number of people that can be built upon in future iterations.

Finally, this is a somewhat new line of research that has yet to be fully explored within college athletics. While it can easily be placed within the body of knowledge on college athletics leadership (Baghurst et al., 2014; Branch, 1990; Burton \& Welty Peachey, 2009, 2013; Robertson 2008; Seidler et al., 1998), it is unique in that most of those studies focus on the duties of ADs or the leadership styles of ADs. Seidler et al. (1998) were the only ones to address how ADs and presidents interact, but used a different methodology and was not solely focused on this topic. Some higher-educational leadership literature discusses the role of the university president in relationship to faculty and other administrators, (Kezar, 2000; Lambert, 2012; Legon, Lombardi, \& Rhoades, 2013) but not with ADs specifically. As a result of the newness of this topic, much of what was learned through this research will guide what can be changed or improved in future iterations. Nonetheless, valuable data were gathered that resulted in an insider's look into the job of an AD and ways in which ADs build relationships with presidents.

\section{Conclusion}

The landscape of college athletics is rapidly changing, which is why so much of this discussion focused on how the information gathered and presented here might impact a changing reality. Bernard (2003), in her advice to presidents overseeing athletics at their institutions, correctly predicted that "hot spots" in forthcoming years would involve "the fundamental role of college athletics higher education," "increasing assertion of legal rights" by student-athletes, "increasingly complex 
business arrangements," "skyrocketing competition" for top head coaches, and "evolving regulatory oversight" by the federal government (2003, p. 33). Media, money, and governing structures (i.e., NCAA) are influencing college athletics in significant ways, and are creating new opportunities and challenges on an almost weekly basis. Therefore, what works now might not work in a decade. However, looking at the results of this study, one can begin to develop a foundation upon which to base future working relationships between ADs and university presidents. Trust and communication, alignment, respect for expertise, and formal and informal relationships have formed what might be considered that foundation.

Much like the relationship building mentioned by Wang et al. (2011), the themes that presented themselves through this study do not exist in every relationship, and will not occur without deliberate thought and effort. Those on the path toward, or already in, athletic administration roles should focus on these now, so that they may be better prepared for the future. Trust and communication, alignment, respect for expertise, and formal and informal relationships might not be the topics that one practices daily in a lower- or middle-manager type role in college athletics. However, if one has no experience thinking about these topics and how to work at them until he or she arrives at the top, there will be difficulty in adjusting to a new role. Therefore, this research has applicability not only to current ADs and presidents, but to those throughout athletic departments, as well as sport management instructors, who can integrate them into athletic administration and leadership courses.

In closing, leadership is a skill best honed through practice. While we can read and write about it indefinitely, until one experiences it firsthand it remains an enigma. Therefore, the best way to prepare ADs for positive relationship dynamics with their presidents is for them to develop them throughout their career at different levels of leadership. While this study indicates four critical pieces to the puzzle, each AD interviewed communicated and practiced them differently. No doubt they each need to exist, but the ways in which they are carried out must be catered to each person individually for optimal success.

\section{References}

Associated Press. (2013, April 5). A timeline of the Rutgers basketball scandal. ESPN.com. Retrieved from http://espn.go.com/espn/wire?id=9139051

Baghurst, T., Murray, E., Jayne, C., \& Carter, D. (2014). Leadership and management skills of junior college athletic directors. Sport Journal, 1.

Bandura, A. (1986). Social foundations of thought and action: A social cognitive theory. Englewood Cliffs, N.J.: Prentice Hall.

Bernard, P. (2003). The athletics equation: A president's bad dream. Change. The Magazine of Higher Learning, 35, 32-33.

Blaikie, N.W.H. (1991). A critique of the use of triangulation in social research. Quality \& Quantity, 25, 111-136. doi:10.1007/BF00145701

Branch, D. (1990). Athletic director leader behavior as a predictor of intercollegiate athletic organizational effectiveness. Journal of Sport Management, 4, 161-173. doi:10.1123/ jsm.4.2.161

Burton, L., \& Welty Peachey, J. (2009). Transactional or transformational? Leadership preferences of division III athletic administrators. Journal of Intercollegiate Sport, 2, 245-259. doi:10.1123/jis.2.2.245

Burton, L., \& Welty Peachey, J. (2013). The call for servant leadership in intercollegiate athletics. Quest, 65(3), 354-371. doi:10.1080/00336297.2013.791870 
Carboni, I., \& Ehrlich, K. (2013). The effect of relational and team characteristics on individual performance: A social network perspective. Human Resource Management, 52, 511-535. doi:10.1002/hrm.21539

Cotrufo, R.J. (2014). Examining the influence of ethical and authentic leadership behaviors of NCAA division I athletic directors (doctoral dissertation). Retrieved from http:// digitalcommons.uconn.edu/disserations

Dirks, K.T., \& Ferrin, D.L. (2002). Trust in leadership: Meta-analytic findings and implications for research and practice. The Journal of Applied Psychology, 87(4), 611-628. PubMed doi:10.1037/0021-9010.87.4.611

Davis, S.M. (1984). Managing corporate culture. New York, NY: Ballinger.

Duderstadt, J. (2000). Intercollegiate athletics and the American university. Ann Arbor, MI: The University of Michigan Press. doi:10.3998/mpub.16522

Eligon, J., \& Pérez-Peña, R. (2015, November 9). University of Missouri protests spur a day of change. The New York Times. Retrieved from http://www.nytimes.com/2015/11/10/ us/university-of-missouri-system-president-resigns.html

ESPN News Services. (2011, November 10). Joe Paterno, Graham Spanier removed. ESPN. Retrieved from http://espn.go.com/college-football/story/_id/7214380/joe-paternopresident-graham-spanier-penn-state

Fagan, K. (2014, August 21). Athletic departments handling sexual assault cases: Never a good idea. ESPNW.com. Retrieved from http://espn.go.com/espnw/news-commentary/ article/11386174/why-athletic-departments-clueless-handling-sexual-assaults

Fossey, E., Harvey, C., McDermott, F., \& Davidson, L. (2002). Understanding and evaluating qualitative research. The Australian and New Zealand Journal of Psychiatry, 36, 717-732. PubMed doi:10.1046/j.1440-1614.2002.01100.x

Ganim, S. (2015, July 7). Athletes allege abuse and racism at University of Illinois. CNN. Retrieved from http://www.cnn.com/2015/07/07/us/illinois-athletics-allegations/

Gladden, J.M., \& Funk, D.C. (2002). Developing an understanding of brand associations in team sport: Empirical evidence from consumers of professional sport. Journal of Sport Management, 16(1), 54-81. doi:10.1123/jsm.16.1.54

Glaser, B.G., \& Strauss, A.L. (1967). The discovery of grounded theory: Strategies for qualitative research. Chicago: Aldine.

Glesne, C. (1998). Becoming Qualitative Researchers: An Introduction. White Plains, NY: Longman.

Governance. (n.d.). National Collegiate Athletic Association. Retrieved from http://www. ncaa.org/governance

Guba, E.C. (1990). The alternative paradigm dialog. In E.C. Guba (Ed.), The paradigm dialog (pp. 17-30). Newbury Park, CA: Sage.

Hardin, R., Cooper, C.G., \& Huffman, L.T. (2013). Moving on up: Division I athletic directors' career progression and involvement. Journal of Applied Sport Management, 5(3), 55-78.

Heyboer, K., \& Sherman, T. (2013, July 23). Rutgers basketball fallout: Report details mistakes, lack of oversight that led to scandal. The Star-Ledger. Retrieved from http:// www.nj.com/rutgersbasketball/index.ssf/2013/07/report_details_mistakes_lack_of_ oversight_that_led_to_rutgers_basketball_scandal.html

Hoy, W., \& Miskel, C. (1987). Educational Administration: Theory, Research and Practice $\left(3^{\text {rd }} E d\right.$.). New York, NY: Random House.

Hsiung, H.H. (2012). Authentic leadership and employee voice behavior: A multi-level psychological process. Journal of Business Ethics, 107, 349-361. doi:10.1007/s10551011-1043-2

Institutional control: So you want to be an AD. (n.d.). National Collegiate Athletic Association. Retrieved from http://www.ncaa.org/governance/institutional-control

Jensen, K.B. (2002). The qualitative research process. In K.B. Jensen (Ed.), A handbook of media and communication research: Qualitative and quantitative methodologies (pp. 235-253). London: Routledge. doi:10.4324/9780203465103 
Kent, A., \& Chelladurai, P. (2001). Perceived transformational leadership, organizational commitment, and citizenship behavior: A case study in intercollegiate athletics. Journal of Sport Management, 15(2), 135-159. doi:10.1123/jsm.15.2.135

Kezar, A. (2000). Pluralistic leadership: Bringing diverse voices to the table. About Campus: Enriching the Student Learning Experience, 5, 6-11.

Kiley, K. (2012a, September 18). The achilles heel. Inside Higher Ed. Retrieved from https:// www.insidehighered.com/news/2012/09/18/unc-president-steps-down-after-two-yearsathletics-scandals

Kiley, K. (2012b, October 4). Searching for an answer. Inside Higher Ed. Retrieved from https://www.insidehighered.com/news/2012/10/04/major-turnover-research-universitypresidencies-could-lead-unconventional-picks

Krauchek, V., \& Ranson, G. (1999). Playing by the rules of the game: Women's experiences and perceptions of sexual harassment in sport. CRSA/RCSA, 36(4), 585-600.

Kraut, A.I., Pedigo, P.R., McKenna, D.D., \& Dunnette, M.D. (1989). The role of the manager: What's really important in different management jobs. The Academy of Management Executive, 3, 286-203. doi:10.5465/AME.1989.4277405

Lambert, S. (2012). The perception and implementation of sustainable Leadership strategies in further education colleges. Journal of Leadership Education, 11, 102-120. doi:10.12806/V11/I2/RF6

Legon, R., Lombardi, J.V., \& Rhoades, G. (2013). Leading the university: The roles of trustees, presidents, and faculty. Change. The Magazine of Higher Learning, 45, 24-32. doi:10.1080/00091383.2013.749144

Lincoln, Y.S., \& Guba, E.G. (1985). Naturalistic Inquiry. Newbury Park, CA: Sage Publications.

McCracken, G. (1988). The long interview (Qualitative research methods series, Vol. 13). Newbury Park, CA: Sage.

McWorthy, L., \& Dryden Henningsen, D. (2014). Looking at favorable and unfavorable superior-subordinate relationships through dominance and affiliation lenses. International Journal of Business Communication, 51, 123-137. doi:10.1177/2329488414525195

National Collegiate Athletic Association. (2014). Division I Steering Committee on governance: Recommended Governance Model. NCAA Division I Steering Committee on Governance Report to Division I Board July 2014. Retrieved from http://www.ncaa. org/sites/default/files/DI\%20Steering\%20Commitee\%20on\%20Gov\%20Proposed\%20 Model $\% 2007 \% 2018 \% 2014 \% 204$.pdf?division=d1

New, J. (2014, November 7). Colleges turn to athletics directors with business backgrounds, but results vary. Inside Higher Ed. Retrieved from https://www.insidehighered.com/ news/2014/11/07/colleges-turn-athletics-directors-business-backgrounds-results-vary

New, J. (2016, March 16). Racial gaps in the Power 5. Inside Higher Ed. Retrieved from https://www.insidehighered.com/news/2016/03/16/black-athletes-wealthiest-conferences-continue-graduate-low-rates[REMOVED HYPERLINK FIELD]

Ohlendorf, P. (2011). Trends in NCAA compliance: Understanding "institutional controls" and legal counsel's role in managing the risks inherent in athletics compliance. Proceedings from the National Association of College and University Attorneys annual conference (June 26-29, 2011), 1-3. Retrieved from http://www-local.legal.uillinois. edu/nacua11/presentations/4G_handout.pdf

O'Keeffe, M., Red, C., Armstrong, K., \& Vinton, N. (2013, May 29). As Julie Hermann mess worsens, calls mount for Rutgers to bring back Tim Pernetti. New York Daily News. Retrieved from http://www.nydailynews.com/sports/college/hermann-critics-rutgersbring-back-pernetti-article-1.1358069

O’Neill, H.M., \& Lenn, D.J. (1995). Voices of survivors: Words that downsizing CEOs should hear. The Academy of Management Executive, 9, 23-33.

Patterson, C. (2015, June 4). NCAA charges UNC with lack of institutional control, extra benefits. CBSSports. Retrieved from http://www.cbssports.com/collegefootball/ 
eye-on-college-football/25205083/ncaa-charges-unc-with-lack-of-institutional-controlin-academic-scandal

Powers, C. (2013, February 20). Explaining the NCAA's "lack of institutional control" charge against Miami. SB Nation. Retrieved from http://www.sbnation.com/collegefootball/2013/2/20/4008392/ncaa-lack-of-institutional-control-definition-miami

Rezaei, M., Salehi, S., Shafieh, M., \& Sabet, S. (2012). Servant leadership and organizational trust: The mediating effect of the leader trust and organizational communication. Emerging Markets Journal, 2, 70-78. doi:10.5195/EMAJ.2012.21

Robertson, J.E. (2008). Leadership, athletic directors and mental toughness. National Junior College Athletic Association Review, 60, 2-6.

Rusaw, A.C. (2000). The ethics of leadership trust. International Journal of Organization Theory and Behavior, 3, 547-569.

Seidler, T.L., Gerdy, J.R., \& Cardinal, B.J. (1998). Athletic director authority in division I intercollegiate athletics: Perceptions of athletic directors and university presidents. International Sports Journal, 2, 36-46.

Schein, E. H. (1985). Organizational culture and leadership. San Francisco, CA: Jossey-Bass.

Shen, W. (2003). The dynamics of the CEO-Board relationship: An evolutionary perspective. Academy of Management Review, 28(3), 466-476.

Skakon, J., Nielsen, K., Borg, V., \& Guzman, J. (2010). Are leaders' well-being, behaviours and style associated with the affective well-being of their employees? A systematic review of three decades of research. Work and Stress, 24, 107-139. doi:10.1080/026 78373.2010 .495262

Smith, M. (2014, June 9). So you want to be a college AD? Sports Business Daily. Retrieved from http://www.sportsbusinessdaily.com/Journal/Issues/2014/06/09/In-Depth/ADmain.aspx $? \mathrm{hl}=\mathrm{AD} \% 20 \mathrm{leadership} \& \mathrm{sc}=0$ [REMOVED HYPERLINK FIELD]

Smith, M. (2015, June 25). SBJ looks inside the AD's office. Sports Business Journal. Retrieved from http://www.sportsbusinessdaily.com/Journal/Issues/2015/06/15/InDepth/AD-lead-in.aspx

Solomon, J. (2015, February 18). Why the NCAA won't adopt concussion penalties - at least not yet. CBS Sports. Retrieved from http://www.cbssports.com/collegefootball/writer/jonsolomon/25073014/why-the-ncaa-wont-adopt-concussion-penalties-at-least-not-yet

Star-Ledger staff. (2013, April 12). Rutgers basketball scandal: The key people who took the fall. The Star-Ledger. Retrieved from http://www.nj.com/news/index.ssf/2013/04/ the_key_players_in_the_rutgers.html

Sturgis, R. (2006). Presidential leadership in institutional advancement: From the perspective of the president and vice president of institutional advancement. International Journal of Educational Advancement, 6, 221-231. doi:10.1057/palgrave.ijea.2150019

Tarter, C.J., \& Hoy, W.K. (1988). The context of trust: Teachers and the principal. High School Journal, 72(1), 17-24.

Tracy, M., \& Strauss, B. (2015, September 30). Court strikes down payments to college athletes. The New York Times. Retrieved from http://www.nytimes.com/2015/10/01/ sports/obannon-ncaa-case-court-of-appeals-ruling.html

Tsui, A.S., Zhang, Z-H., Wang, H., Xin, K.R., \& Wu, J.B. (2006). Unpacking the relationships between CEO leadership behavior and organizational culture. The Leadership Quarterly, 17, 113-137. doi:10.1016/j.leaqua.2005.12.001

Teven, J.J., McCroskey, J.C., \& Richmond, V.P. (2006). Communication correlates of perceived Machiavellianism of supervisors: Communication orientations and outcomes. Communication Quarterly, 54, 127-142. doi:10.1080/01463370600650829

Wang, H., Tsui, A.S., \& Xin, K.R. (2011). CEO leadership behaviors, organizational performance, and employees' attitudes. The Leadership Quarterly, 22, 92-105. doi:10.1016/j. leaqua.2010.12.009

Whisenant, W.A., \& Pedersen, P.M. (2004). The influence of managerial activities on the success of intercollegiate athletic directors. American Business Review, 22(1), 21-26. 
Whisenant, W.A., Pedersen, P.M., \& Obenour, B.L. (2002). Success and gender: Determining the rate of advancement for intercollegiate athletic directors. Sex Roles, 47(9/10), 485-490. doi:10.1023/A:1021656628604

Wolverton, B. (2014). NCAA plan would give new powers to biggest conferences. The Chronicle of Higher Education, 60(19), A14.

Wong, G. (2014, June 9). The path to the athletic director's office. Sports Business Daily. Retrieved from http://www.sportsbusinessdaily.com/Journal/Issues/2014/06/09/InDepth/Wong-column.aspx?hl=AD\%20leadership\&sc $=0$

Zernike, K. (2013, April 4). Pressure builds on Rutgers president. The New York Times. Retrieved from http://www.nytimes.com/2013/04/05/sports/ncaabasketball/rutgerspresident-robert-barchi-faces-more-pressure-over-coach-mike-rice.html 